\title{
Carnets
}

Revue électronique d'études françaises de l'APEF

Première Série - 4 Numéro Spécial | 2012

Invasions \& Évasions

\section{António Lobo Antunes e Christine Angot - trauma, interdito e renovação do romance}

Eunice Cabral

\section{CpenEdition}

12 Journals

Edição electrónica

URL: http://journals.openedition.org/carnets/7900

DOI: $10.4000 /$ carnets. 7900

ISSN: 1646-7698

Editora

APEF

Edição impressa

Data de publição: 1 Junho 2012

Paginação: 291-301

Refêrencia eletrónica

Eunice Cabral, « António Lobo Antunes e Christine Angot - trauma, interdito e renovação do romance », Carnets [Online], Première Série - 4 Numéro Spécial | 2012, posto online no dia 23 junho 2018, consultado o 21 abril 2019. URL : http://journals.openedition.org/carnets/7900 ; DOI : 10.4000/ carnets. 7900

\section{(c) (1) \&}

Carnets est mis à disposition selon les termes de la licence Creative Commons - Atribution - Pas d'utilisation commerciale 4.0 International. 


\title{
ANTÓNIO LOBO ANTUNES E CHRISTINE ANGOT \\ Trauma, interdito e renovação do romance
}

\author{
EUNICE CABRAL \\ Universidade de Évora \\ eunice.cabral@netcabo.pt
}

\section{Resumo}

Este estudo visa analisar os discursos romanescos de duas obras de autores contemporâneos, que se distinguem pela representação quer do trauma quer do interdito a este ligado. Para tal, analisaremos Os Cus de Judas (1979), de António Lobo Antunes (ALA), e Pourquoi le Brésil? (2002), de Christine Angot (CA). Não existem, de facto, semelhanças óbvias entre os dois romances, que se inserem em duas obras romanescas com características muito diversas (discursos marcados pelo género, cenários urbanos diferentes, inserção cronológica distinta, etc.); mas têm pelo menos em comum figurações do trauma que interpelam o romance e o renovam consideravelmente: o romance de ALA tem como centro o trauma de uma guerra colonial e o de CA o trauma do incesto.

\section{Abstract}

This study aims at analyzing two novelistic works by contemporary authors, different in their representation of trauma and the forbiddance attached to it. In order to do so, we will analyze Os Cus de Judas (1979) by António Lobo Antunes (ALA), and Pourquoi le Brésil? (2002) by Christine Angot (CA). Despite de fact that there are no obvious similarities between the two novels - which are very different romanesque works (gender marked discourses, different urban sceneries, distinct chronological settings, etc.) - at least they have in common some trauma figurations that considerably challenge and renew the novel (the ALA's novel tells us about the trauma of a colonial war whereas the CA's novel deals with the trauma of incest).

Palavras-chave: trauma, interdito, renovação do romance contemporâneo.

Keywords: trauma, forbiddance, renovation of the contemporary novel. 
1. A representação do trauma e do interdito que lhe é inerente estabelecem elos de ligação e de comparação entre dois romances marcadamente dissemelhantes noutros aspectos como são os casos de Os Cus de Judas (1979) de António Lobo Antunes (ALA) e de Pourquoi le Brésil? (2002) de Christine Angot (CA).

Antes de analisarmos a representação mencionada nos dois romances em questão, é necessário ter em conta o conceito de trauma. Para além de um conhecimento do conceito de trauma em termos psíquicos relativos aos âmbitos da psiquiatria e da psicoterapia, que é alheio a esta análise e cujo aprofundamento científico não mencionaremos, será mais produtivo avaliar este conceito de modo abrangente e generalista, na medida em que se trata de uma análise cujo cerne é constituído por textos romanescos que lidam com esta noção em termos da sua concretização vivida e experimentada por uma ou várias personagens e não de um estudo científico sobre o conceito de trauma.

Por conseguinte, entendemos de modo abrangente que um indício inequívoco da existência do trauma consiste na impressão e na vivência de um transtorno vivido com uma intensidade muito acentuada, que impossibilita ao indivíduo uma resposta adequada posteriormente, sempre que tal transtorno é reactivado. Esta "marca" - que é, no fundo, uma recordação de uma cena ou de várias cenas passadas, transfigurada pelo sofrimento e pela impossibilidade de a reconverter de modo satisfatório e em seu proveito na personalidade de quem a "sofre" recorrentemente - insiste em reaparecer, não permitindo ao indivíduo lidar de modo equilibrado com a experiência presente, que é tornada distorcida, indiferenciada, ou mesmo "apagada", pelo trauma.

"Trauma" é o termo usado para descrever um choque (ou uma série de choques), que deixa uma marca dolorosa e profunda no cérebro do paciente sob a forma de uma espécie de abcesso psicológico. É uma ferida psicológica ainda por cicatrizar que, quando reavivada, pode dominar todo o funcionamento mental e físico de um indivíduo (Servan-Schreiber, 2010: 260).

Neste sentido, as situações traumatizantes podem ser despoletadas por acontecimentos presentes, que se ligam de diferentes formas ao passado considerado traumático e que, como tal, comprometem esse mesmo presente, tornando-o uma repetição fantasmática de acontecimentos passados, imobilizando e estagnando a vida atual.

Vejamos a definição de trauma segundo o Vocabulário da Psicanálise da autoria de Laplanche e Pontalis: trauma é "uma ferida com efracção". E traumatismo significa "as consequências no conjunto do organismo de uma lesão resultante de uma violência externa" (Laplanche e Pontalis, 1970: 678-679). Freud transpôs para o plano psíquico as 
três significações implicadas na noção de trauma: "a de um choque violento, a de uma efracção e a de consequências sobre o conjunto da organização" (Ibid : 679).

Refira-se que, nos escritos de Freud, não se pode falar de acontecimentos traumáticos de maneira absoluta pois eles não se formam sem um denominador comum, a "susceptibilidade própria do indivíduo" (Ibid : 680). Esta consiste no conflito psíquico, que impede o indivíduo de integrar, na sua personalidade consciente, a experiência penosa, que é representada, no psiquismo, como um "corpo estranho" (Ibid : 680). No trauma, o ego é atacado de dentro, tal como é atacado de fora (Ibid : 683).

A cena traumática pode não estar presente na consciência mas o seu rasto não é apagado, sobretudo porque são a passividade, por um lado, e a imposição por parte de outros, por outro, que a torna crucial na vida psíquica. De facto, o sujeito não foi agente dessa experiência; não teve liberdade de escolha e sofreu às mãos de outro ou de outros. De facto, "o estado de passividade é correlativo de uma não-preparação", que, se existisse, permitiria a integração da experiência, anulando o seu carácter traumático (Ibid : 611).

2. Ora, os dois romances em análise são autodiegeses em que o discurso do eu narra uma experiência traumática.

A autodiegese da autoria de ALA consiste na narração da experiência de uma guerra, a guerra colonial portuguesa, que é percepcionada por este eu-narrador como perdida no momento em que nela começa a participar e, como tal, é entendida como um conjunto inútil de actos violentos. Apesar de esta ser apresentada como uma experiência delimitada no tempo - o narrador-protagonista esteve em Angola como médico combatente durante menos de três anos -, afecta de modo continuado e consistente toda a sua relação com a realidade e com o mundo, mesmo muito depois de ter cessado como experiência directa.

É nesse sentido que pode ser considerada uma experiência traumática pois o cenário e as acções vividas, nesse período, provocam um conjunto negativo de sensações e de emoções, que se perpetua no tempo, dando azo a que o narrador-protagonista não viva o presente, posterior à sua participação na guerra colonial, tornando-o alguém que não está notoriamente disponível para a novidade que qualquer tempo presente implica. Por outras palavras: o presente da narração, que, em Os Cus de Judas, corresponde a uma noite passada a falar com uma mulher desconhecida num bar e, em seguida, na ida para o apartamento do protagonista até cedo, de manhã, é um tempo "morto" no sentido em que qualquer acção é irrelevante, ou seja, não tem a possibilidade de inscrever outra percepção da realidade senão a já enquistada pelo trauma, não dando lugar a alterações na configuração deste protagonista pela eventual integração de novos elementos ou dados decorrentes da situação presente. 
Com efeito, o cenário e respectivas experiências, que explicam a vida do protagonista no presente, situam-se no passado da guerra para o qual remete todo o seu discurso. Assim sendo, não estamos perante uma simples rememoração de um passado, mas de um passado que é evocado em "modo" traumático, digamos assim, no sentido em que suga toda a energia vital do indivíduo, não o deixando com capacidade para apreender sequer os acontecimentos presentes. Dito de outro modo: o presente encontra-se "refém" de uma narrativa, que lhe é estranha, a do passado de guerra.

3. Apesar de o trauma do incesto ser de natureza muito distinta do trauma provocado por uma guerra (que, como já dissemos, é tida como perdida pelo protagonista, desde o início), os seus efeitos são semelhantes em termos da cena revivida fantasmagoricamente pelo sujeito que se viu "atirado" e "mergulhado" em circunstâncias não escolhidas, que o humilham pela incapacidade de se defender, com o elemento acrescido de a sua sensibilidade não permitir elaborar de modo positivo e em benefício próprio a cena indesejada, não a reconfigurando, o que, a ter lugar, Ihe anularia a importância.

A guerra, que é representada de modo omnipresente no romance de ALA e a sujeição ao incesto no romance de CA têm em comum protagonistas passivos, levados "às cegas" para um cenário escolhido por outros, os seus agentes, que, por sua vez, imprimem na carne e no espírito uma experiência contrária à dignidade do sujeito, não apenas provocando sofrimento, como pondo em "cheque" uma vida futura, que deveria estar vocacionada, se não para a felicidade, pelo menos para a paz de espírito. Ambas só seriam possíveis se o sujeito estivesse livre para percepcionar a vida presente de modo mais activo, ou seja, tendo em conta os dados do "aqui e agora".

Em ambos os romances, não é apenas a vida presente em geral que inconscientemente se encontra refém da cena traumática, que se expandiu e que aprisionou de tal maneira a percepção de cada um dos sujeitos em causa que ocupa todo o espaço e o tempo de vida, tornando-os irrelevantes. Mais significativo ainda é o fenómeno, reconhecível em ambos os romances, em que a cena traumática inscreve "a impossibilidade de vida" no cerne da intimidade individual, cuja expressão mais evidente é o amor.

No romance de ALA, a impossibilidade do amor surge em duas situações bem definidas uma é a impossibilidade de regresso a casa do protagonista, casa essa constituída por um casal (ele e a mulher), formado antes de partir para a guerra: trata-se da impossibilidade do regresso ao casamento realizado e vivido (ainda que muito fugazmente) antes da partida para a guerra colonial. A outra situação, bem delimitada também, consiste na impossibilidade de encontro íntimo e/ou amoroso com a mulher, até então desconhecida, encontrada no bar e interlocutora da narrativa durante o tempo da diegese: a noite passada 
no bar e, posteriormente, o período de encontro físico no apartamento do protagonista até a companheira ocasional partir, já de madrugada.

No romance de CA, o incesto, que efectivamente é apenas mencionado explicitamente em dois passos curtos da narrativa romanesca, funciona como cena traumática original e, como tal, expande-se através de toda a percepção que a protagonista tem da sua própria vida e, por extensão, da realidade e do mundo, marcada pelas figuras da falta de energia e de entusiasmo e da ausência irremediável de "novidade", impossibilitando, destes modos, o sucesso de uma vida vivida no presente e, por consequência, tornando inviável o amor.

4. A inviabilidade da vida no presente e, por arrastamento, a do amor experimentado no presente decorrem do facto de as vivências traumáticas implicarem a noção de descontinuidade. A fluência vivida em que as experiências do sujeito deveriam acontecer e que, como tal, poderiam ser integradas de modo progressivo e evolutivo (e até, eventualmente, criativo) é interrompida pela cena que se torna traumática exactamente porque não é integrada na personalidade do indivíduo e é representada como um corpo estranho, indesejado, invasor da vontade e da dignidade do sujeito.

A descontinuidade, daí decorrente, articula-se com o conflito vivido pelo sujeito, que tem uma representação contraditória na medida em que se, por um lado, inibe todo o desenvolvimento da personalidade, por outro lado, o conflito traumático parece estar esquecido. Com efeito, o sujeito traumatizado tem acesso às consequências do trauma, ou seja, eventualmente às inibições, às repetições de experiências negativas e, também, à falta de confiança em relação ao facto de que a sua vida possa, efectivamente, ser vivida de forma positiva. Assim, vivendo na ilusão de que o conflito passado está "arrumado" e, por esta razão, desactivado, o interdito, que acompanha o trauma, é consequência do conflito não resolvido, distorcido e activado de modo inconsciente.

5. O conceito de trauma pode, ainda, ser articulado com a noção que Walter Benjamin criou ao se referir à "experiência do homem moderno como experiência vivida do choque", que é uma experiência de "crise" e de ruptura com a tradição e com os fundamentos anteriores (Cantinho, 2002: 12). É uma experiência fragmentária, atomizada e fantasmagórica, com uma conotação de esvaziamento da experiência contrária à experiência autêntica (ibid: 132), que ocorre num "tempo homogéneo e vazio" (Ibid : 99).

Trauma e "experiência vivida do choque" tornam-se noções complementares, que permitem interpretar os dois discursos romanescos em análise. Tendo tido lugar no passado, produzem o "efeito de uma transfiguração do espaço e do tempo" (Ibid: 99), tanto o correspondente à cena ou às cenas passadas como às presentes. 
Deste modo, a transfiguração de cariz traumático imobiliza o presente; torna-o dependente de forma doentia desse passado em que o sujeito foi tomado como objecto de uma decisão de outro ou de outros. No caso do romance de ALA, o sujeito foi e é o estado português, que instituiu a guerra; no caso do romance de CA, foi e é o pai como figura tutelar de uma acção da qual a protagonista é incapaz de regressar. Aliás, ambos os protagonistas não regressam, de facto, da cena traumática. Lá permanecem de certo modo irreconhecíveis a si mesmos e incapazes de se reconstruir e, pior, impossibilitados de pertencerem a si mesmos. Tanto o pai de Christine no romance de CA, como o estado português (de certo modo, ambos são pais tirânicos, insensíveis e cruéis) são entidades omnipotentes e omnipresentes porque são doadoras de identidades indesejadas mas impostas, tendo a capacidade de infligir uma ferida, que não sara, ao filho e à filha.

No romance de ALA, o protagonista encontra-se como que hipnotizado pela sua experiência da guerra e pelo fracasso da sua vida que se the seguiu. Todo o discurso dirigido à mulher até então desconhecida está centrado no passado não escolhido relativo à guerra e no presente fracassado em que o sujeito parece não estar verdadeiramente presente: "Nunca estamos onde estamos, não acha?" (Antunes, 2004: 120), comenta o protagonista para a sua interlocutora enquanto vão de elevador para o seu apartamento.

A figuração de um narrador ou focalizador alheado do tempo e da acção presentes molda variadíssimas cenas neste romance, constituindo até as mais recorrentes da ficção de ALA. Dois dos seus romances (Manual dos Inquisidores e Sôbolos rios que vão), aliás, iniciam-se com a representação desta descontinuidade, que aponta para um conflito latente no modo como o narrador percepciona o lugar, o espaço e o seu próprio eu.

Voltemos ao romance em análise: é significativa a descrição do seu próprio apartamento, feita pelo protagonista, no caminho para casa no automóvel com a companheira, em que apresenta o espaço como desabitado e impessoal, comentando ainda que tem dificuldade em aceitar que viva ali:

[...] acontece-me permanecer aqui [no apartamento] alguns minutos, surpreendido e incrédulo, entre as caixas do correio e o elevador, procurando em vão um sinal meu, uma pegada, um cheiro, uma peça de roupa, um objecto, na atmosfera vazia do vestíbulo, cuja nudez silenciosa e neutra me desarma. [...] existe sempre em mim a suspeita tenaz de que me vão expulsar, de que ao entrar em casa encontrarei outros móveis no lugar dos meus móveis, livros desconhecidos nas estantes, uma voz de criança algures no corredor, um homem instalado no meu sofá a erguer para mim um olhar de perplexidade indignada (Antunes, 2004: 119-120). 
No romance de CA, a figura do trauma, decorrente do incesto, surge representada, não de modo directo (visto que, como dissemos anteriormente, é apenas referida de modo literal em dois passos do romance), mas nas suas consequências indirectas, sob a forma do cansaço extremo e do esgotamento. O romance começa com o período seguinte: "J'étais tellement fatiguée, et je n'en pouvais tellement plus, que j'en étais arrivée à la conclusion qu'il fallait que j'organise ma vie en fonction d'un bien-être physique" (Angot, 2002: 13).

Esta noção de um bem-estar físico torna-se um ideal inatingível para a protagonista, que se vê destituída de forças para levar a cabo uma vida no presente na qual o que vai acontecendo é excessivo e simultaneamente destituído de significação:

cette fois je craque, ah là, cette fois, je craque. Les gens craquent, il y a des tas de gens qui craquent. II y a des tas de gens qui sont épuisés. II y a un livre de Pavese qui s'appelle Le Métier de vivre, les gens sont épuisés par le métier de vivre, ils ne supportent plus, ils ne peuvent plus. Et quand la mécanique s'enraye ils craquent, moi je craquais en permanence, j'avais atteint ce stade. J'avais envie de crier dans la rue: vous ne vous en rendez pas compte, que vous êtes tous en trop? (Angot, 2002: 27)

Toda a narrativa é enunciada no presente como se a protagonista (também de nome Christine como a autora) escrevesse à medida que vai vivendo, percepcionando e, sobretudo, sentindo os acontecimentos, ou seja, parece escrever à medida que experimenta a realidade presente. Sabemos que tal não é verdadeiro, que a escrita é posterior necessariamente ao que viveu, mas a narrativa quer captar a imediaticidade dos factos porque só pela representação imediata do que está presente (como se qualquer intermediário falsificasse o vivido) consegue comunicar aquela figura mais original de todo 0 romance, que é o esgotamento que a cidade de Paris provoca na protagonista pela ausência de vida e pela repetição contínua de actos e de acontecimentos tornados insuportáveis. No entanto, o leitor começa a compreender que o esgotamento de todas as forças já vem de um tempo anterior em que a protagonista vivia em Montpellier. Acontece que o esgotamento é acentuado em Paris, cidade que cria situações, encontros, sentimentos (ou a falta deles), emoções que esvaziam, diminuem, enfraquecem quem quer que seja, segundo a perspectiva da protagonista.

Neste sentido, a narrativa opõe-se à de ALA em que a narrativa principal assenta na intensidade com que descreve e narra o passado e em que o presente é insignificante, e até desprezado, na medida em que, nesse presente, nada é importante, excepto reconstituir o tempo pela memória magoada e ferida, pela evocação e pela presentificação, que permitem, uma e outra vez, rememorar as cenas traumáticas do passado. No romance de ALA, o presente encontra-se saturado do passado através de um prolongamento fantasmático das 
cenas de guerra no qual tem lugar uma significação deste presente por empréstimo devido à contaminação claramente de cariz traumático (quer dizer, sem base real) em que esse passado se expande sem limites, invadindo e sugando a vida actual do protagonista.

No romance de $\mathrm{CA}$, o presente é representado como um tempo em que os acontecimentos quotidianos tornam a vida um "inferno": "J'étais tellement à bout que, à l'époque, j'aurais aimé qu'on m'emporte sur une civière ou dans une clinique"' (Angot, 2002: 13), o que faz da protagonista um ser à beira da ruptura: "C'était trop. Je ne tenais plus. [...] J'étais épuisée. Je n'arrivais plus à me reposer par moi-même" (Ibid: 13).

A incapacidade de continuar a viver nos moldes até então conhecidos encontra-se inscrita na narrativa, mas esta impossibilidade (a de continuar a viver deste modo) tem um acontecimento antecedente, que é recalcado: a cena traumática original relativa ao incesto. Aliás, a protagonista explica esta ligação, ao dizer a um conviva de um jantar parisiense, mundano e fútil, que teve lugar há anos, antes do presente da actual narrativa, que é porque dormiu com o seu pai que tem que fazer psicanálise, neste caso preciso, que não consegue deixar de estar esgotada e que não consegue viver, apesar de o companheiro de jantar a ter prevenido que, segundo a sua opinião, quem começa a fazer análise (leia-se, psicanálise) nunca mais encontrará a saída, ou seja, nunca mais deixará de a fazer sem que consiga evoluir ou, eventualmente, "melhorar" a sua vida (Angot, 2002: 204).

Por conseguinte, em ambos os romances, o presente não tem a possibilidade de ser vivido; o que os distingue é a preponderância e a intensidade do tempo escolhido para ser narrado e representado: em Os Cus de Judas, é o passado; em Pourquoi le Brésil?, é o presente.

Nos dois romances, o amor sobressai como a figura que condensa com mais intensidade a incapacidade de lidar com a vida presente. Em Os Cus de Judas, o narradorprotagonista percepciona a mulher que acaba de conhecer como alguém esvaziado de individualidade, uma mulher-coisa, igual a tantas outras mulheres com quem se cruzou e se cruzará. Esta é a representação escolhida para um fenómeno preponderante na ficção deste autor, a inviabilidade do amor no tempo presente.

No romance da autora francesa, o amor tem lugar na relação amorosa da protagonista com Pierre Louis Rozynès, mas esta relação irá claramente agravar a vida da protagonista, esgotando-a mais ainda e tornando o seu quotidiano impossível pelos factores negativos e disfóricos. De um certo ponto de vista, a narrativa é circular porque o esgotamento inicial é uma antecipação do que se seguirá. A protagonista, aliás, avisa, nas primeiras frases da narrativa, que, para organizar a sua vida em função da sua necessidade de descanso (o bem-estar físico que menciona), terá que evitar tudo o resto, quer dizer, o amor (Angot, 2002: 13), o que não cumprirá e, por consequência, ficará cada vez mais esgotada, não havendo progresso benéfico. 
Eis o final do romance:

[...] en 85 j'avais donné rendez-vous à mon père ici, je reconnaissais bien, je reconnaissais bien cet angle-là, la gare fait un $\mathrm{L}$, je me revoyais en train de sortir de la gare et de revoir mon père après plusieurs années, c'était bizarre de revoir cette gare vingt ans après, avec tout le temps qui a passé depuis, et que rien n'ait changé. C'est ça surtout (Angot, $2002: 251-252$ ).

6. Assim, a sintaxe e a semântica narrativas estão organizadas em função da crise traumática da personagem central, que vai determinar uma manipulação da fábula a ser contada, decorrente da manipulação do sujeito. Como afirma o estudioso do romance moderno e contemporâneo, Wladimir Krysinski: "a crise traumática da personagem central (a "descarga" da sua decepção) determina uma manipulação da fábula [...] e uma manipulação do sujeito" (Krysinski, 1982: 166-167). No entanto, ao contrário de narrativas romanescas em que estes dois tipos de manipulação são reconhecíveis - falamos dos romances de Henry James, analisados também por Krysinski -, nos romances em análise, o de ALA e o de CA, a manipulação da fábula leva a uma singularização do sujeito de tipo negativo e indiferenciado, tendo em conta que o processo de cognição do presente se encontra como que "congelado", "fixado", "imobilizado". Por outras palavras: não chega a constituir um processo de cognição, mas constitui uma repetição fantasmaticamente transfigurada da cena traumática original, entretanto ou excessivamente presente (em Os Cus de Judas) ou falsamente esquecida (em Porquoi le Brésil?).

$\mathrm{Na}$ nossa perspectiva, tal diferença reside no facto de ambos os romances em análise se encontrarem enquadrados pela "experiência vivida do choque", típica do século XX, sobretudo da segunda metade de Novecentos, enquanto, nos romances de Henry James, o tempo aludido é claramente diferente, na medida em que este presente é ainda um tempo de cognição e, por conseguinte, um tempo em que têm lugar acontecimentos presentes, moldados pelo "crescimento da verdade", tão caro às convicções deste autor.

Neste sentido, a saída do trauma é realizada pela escrita nos dois romances contemporâneos que temos vindo a analisar. É escrevendo, comunicando pelo discurso descentrado de um sujeito que não consegue lidar com o seu presente, que se dirige a um leitor eventualmente ideal, que se dá a "descarga" da sua profunda decepção em relação à sua vida actual. É evidentemente uma saída simbólica, que não tem fim à vista, na medida em que cada romance de cada um destes dois autores vai reactualizando o trauma no discurso romanesco de um novo romance, se tivermos em conta as obras romanescas em causa. 
O aspecto verdadeiramente positivo e novo é o referente à inovação do romance, na medida em que a descontinuidade e o conflito, decorrentes da intensificação das cenas traumáticas ou a falsa ausência de consciência da inscrição do trauma, que estão no centro da percepção da realidade exterior e de si mesmo, nos termos em que foram acima mencionados, geram ironicamente, nestes dois romances, discursos romanescos fortemente inovadores. De facto, permitem operar e criar uma ruptura decorrente ("alimentada") pelo trauma e pelo respectivo interdito, o que modeliza um discurso que não apenas narra de forma eficaz e original o indizível "condenado" a não encontrar a unidade, ou seja, se se quiser, a passar ao lado, de forma disfórica, de formas e de figuras positivas, como também expõe sem pudor uma falha, a de uma autenticidade que parece repetidamente escapar ao sujeito traumatizado. 


\section{Bibliografia}

ANGOT, Christine (2002). Pourquoi le Brésil?. Paris: Éditions Stock.

ANTUNES, António Lobo (2004). Os Cus de Judas. Lisboa: Publicações Dom Quixote.

CANTINHO, Maria João (2002). O Anjo Melancólico - Ensaio sobre o conceito de alegoria na obra de Walter Benjamin. Lisboa: Angelus Novus.

KRYSINSKI, Wladimir (1981). Carrefour de signes: essais sur le roman moderne. La Haye: Mouton Éditeur.

LAPLANChE, J. e PONTALIS, J.-B. (1970). Vocabulário da Psicanálise. Lisboa: Moraes Editores. SERVAN-SCHREIBER, David (2010). Anti-cancro - uma nova maneira de viver. Lisboa: Caderno. 
